\title{
Correction to: How is the Pharmaceutical Industry Structured to Optimize Pediatric Drug Development? Existing Pediatric Structure Models and Proposed Recommendations for Structural Enhancement
}

\author{
Thomas Severin ${ }^{1}$. Solange Corriol-Rohou ${ }^{2}$. Christina Bucci-Rechtweg ${ }^{3}$ Kristina an Haack ${ }^{4}$ \\ Sabine Fuerst-Recktenwald ${ }^{5} \cdot$ Pirkko Lepola $^{6} \cdot$ Ensio Norjavaara $^{7} \cdot$ Martine Dehlinger-Kremer $^{8}$ on behalf of the \\ EFGCP Children's Medicines Working Party · Sebastian Haertter ${ }^{9}$. S. Y. Amy Cheung ${ }^{10}$ on behalf of the IQ Pediatric \\ Working Group
}

Published online: 20 April 2020

(c) The Author(s) 2020

\section{Correction to: Therapeutic Innovation \& Regulatory Science https://doi.org/10.1007/s43441-020-00116-4}

The article How is the Pharmaceutical Industry Structured to Optimize Pediatric Drug Development? Existing Pediatric Structure Models and Proposed Recommendations for Structural Enhancement, written by Thomas Severin et al. was originally published electronically on the publisher's internet portal on February 6, 2020 without open access. With the author(s)' decision to opt for Open Choice the copyright of the article changed on April 22, 2020 to (C) The Author(s)
2020 and the article is forthwith distributed under a Creative Commons Attribution 4.0 International License https://creat ivecommons.org/licenses/by/4.0/), which permits use, sharing, adaptation, distribution and reproduction in any medium or format, as long as you give appropriate credit to the original author(s) and the source, provide a link to the Creative Commons license, and indicate if changes were made.

Publisher's Note Springer Nature remains neutral with regard to jurisdictional claims in published maps and institutional affiliations.

The original article can be found online at https://doi.org/10.1007/ s43441-020-00116-4.

Thomas Severin

thomas.severin@novartis.com

1 Global Drug Development, Novartis Pharma AG, Novartis Campus, 4002 Basel, Switzerland

2 Global Regulatory Excellence, AstraZeneca, Paris, France

3 Global Health Policy, Regulatory Affairs, Novartis Pharmaceuticals Corporation, East Hanover, NJ, USA

4 R\&D/Clinical Development Rare Diseases, Sanofi/Genzyme, Chilly-Mazarin, France

5 Product Development Neurology, F. Hoffmann-La Roche Ltd., Basel, Switzerland
6 Department of Children and Adolescents, Helsinki University Hospital, Helsinki, Finland

7 Global Medicines Development, AstraZeneca, Mölndal, Sweden

8 Pediatric Development, Synteract, \& EUCROF, Munich, Germany

9 Translational Medicine \& Clinical Pharmacology, Boehringer-Ingelheim, Ingelheim, Germany

10 Certara, Princeton, NJ, USA 